\title{
Recent advances in the entirely subcutaneous ICD System
}

\section{Markus Bettin*, Florian Reinke, Benjamin Rath, Julia Köbe and Lars Eckardt}

Address: Division of Clinical and Experimental Electrophysiology, Department of Cardiology and Angiology, University Hospital Münster, AlbertSchweitzer-Campus 1, Gebäude A1, 48149 Münster, Germany

*Corresponding author: Markus Bettin (markus.bettin@ukmuenster.de)

FI000Prime Reports 2015, 7:46 (doi:10.12703/P7-46)

All FI000Prime Reports articles are distributed under the terms of the Creative Commons Attribution-Non Commercial License (http://creativecommons.org/licenses/by-nc/3.0/legalcode), which permits non-commercial use, distribution, and reproduction in any medium, provided the original work is properly cited.

The electronic version of this article is the complete one and can be found at: http://fl000.com/prime/reports/m/7/46

\begin{abstract}
The entirely subcutaneous implantable cardioverter defibrillator $\left(S-I C D^{\circledR}\right)$ is emerging as a widely accepted therapeutic alternative to a conventional implantable cardioverter defibrillator (ICD) for prevention of sudden cardiac death. Essentially, the $S-I C D^{\circledR}$ is promising in terms of reduction of electrode-related complications such as lead failure and infections. The conventional transvenous ICD has proven efficacy in various randomized clinical trials. The first results of S-ICD ${ }^{\circledR}$ studies confirm efficacy and safety in primary and secondary prevention as well. Owing to basic differences between $S-I C D^{\circledR}$ and transvenous ICD—such as limited programming options and lack of pacing-not all patients are eligible for the $S-I C D^{\circledR}$. Concerns exist regarding inappropriate shocks due to $T$-wave oversensing, dimensions of the device, and shorter battery longevity. However, the S-ICD ${ }^{\circledR}$ should be considered a useful supplementation of ICD therapy in those patients at risk for sudden cardiac death who are not expected to require pacing due to bradycardia or antitachycardic pacing.
\end{abstract}

\section{Introduction}

Sudden cardiac death (SCD) remains a major cause of death in Western societies, and the estimated incidence is $50-100$ per 100,000 in the general population [1]. Since the first implantation of an ICD in 1980 [2], ICD therapy has been firmly established in primary as well as in secondary prevention of SCD [3-5]. More than 100,000 ICD systems are implanted worldwide each year. However, the right ventricular placed endocardial lead remains the weak point of ICD technology because of procedural and long-term complications such as pneumothorax, cardiac tamponade, lead dislocation, lead malfunction, infection, or venous occlusion (or a combination of these) [6,7]. The longevity of endocardial leads varies in different trials from $91-99 \%$ at 2 years, $85-98 \%$ at 5 years, and $60-72 \%$ at 8 years [8]. Extraction of chronically implanted leads remains a difficult procedure with associated high morbidity and mortality [9]. In particular, potential lead adhesions increase the risk during extraction procedures. Hence, an entirely subcutaneous ICD System has been designed to avoid these specific lead-related complications.
Approved in 2009, the first S-ICD in Germany was implanted in June 2010 at our institution. The subcutaneous system is recommended for therapy of ventricular tachyarrhythmias in patients who do not need antibradycardic or antitachycardic pacing (ATP).

\section{Functionality of the subcutaneous implantable cardioverter defibrillator}

The S-ICD System (SQ-RX 1010, Boston Scientific, USA) consists of a generator and a tripolar shock lead (9 French), which are both implanted subcutaneously. Commonly, the generator is placed in the left midaxillary line at the same level of the processus xiphoideus (that is, fifth to sixth intercostal space), whereas the lead, which combines sensing and defibrillating components, is positioned parallel to the left side of the sternum with the tip at the junction of sternum and manubrium (Figure 1). The electrode at the xiphoid is the anchoring point for the lead, so the tip does not necessarily go up as high as the manubrium. In initial studies by Bardy and colleagues [10], this configuration was shown to be as effective as a transvenous ICD for 
Figure I. Novel position of the entirely subcutaneous implantable cardioverter defibrillator

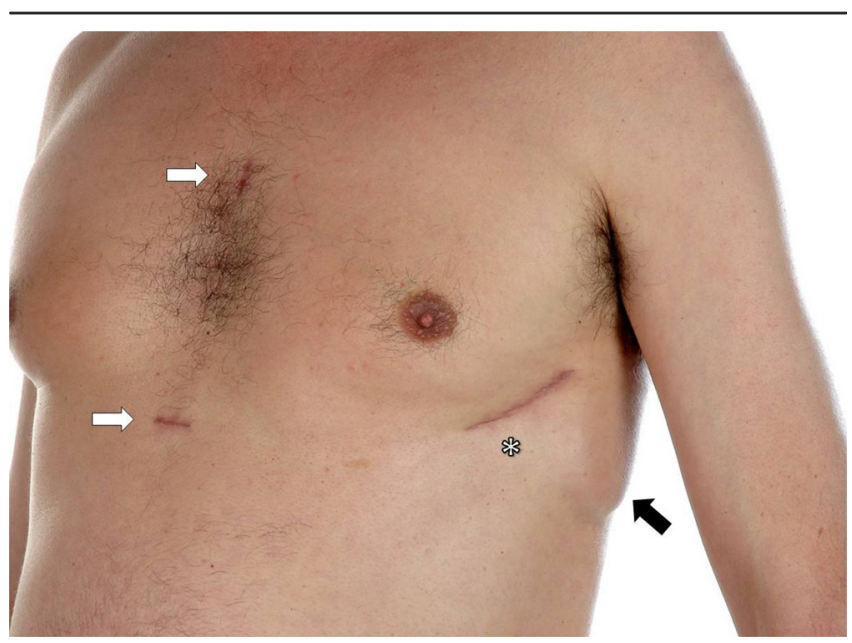

Two incisions are made for the subcutaneous electrode (white arrows), and one incision is made to create the device pocket in the anterior axillary line (asterisk). The subcutaneous implantable cardioverter defibrillator can is finally positioned in the left anterior/midaxillary line (black arrow).

terminating induced ventricular fibrillation (VF). A right parasternal position might be favorable in some cases, particularly to get more left ventricular heart muscle into the defibrillation field in patients with a slim heart in the mid-sagittal position [11]. Knops and colleagues [12] showed that a two-incision technique, which avoids the superior parasternal incision, is a safe and efficacious alternative for S-ICD implantations. By the use of anatomic landmarks, it is possible to dispense with X-ray fluoroscopy during the implantation procedure. As a result of the subcutaneous position, a higher energy is required for termination of detected arrhythmias [10]; therefore, the system provides a nonprogrammable, maximum-energy biphasic shock of $80 \mathrm{~J}$. Accordingly, the impulse generator is heavier (145 g) and larger than that of modern conventional transvenous ICD systems (Figure 2). Up to five shocks per episode can be delivered by the system. The shock waveform is biphasic, with a fixed tilt of $50 \%$. The device is designed to automatically select the appropriate polarity for therapy, but polarity can be switched manually. If the shock fails to convert the arrhythmia, polarity is automatically reversed for each successive shock.

Its novel position on the left lateral side of the thorax and higher generator volume may have an impact on quality of life. However, this aspect of the new system has not been well studied. The manufacturer estimates a battery longevity of about 5 years, which is less than in
Figure 2. Subcutaneous implantable cardioverter defibrillator (ICD) system versus different transvenous devices

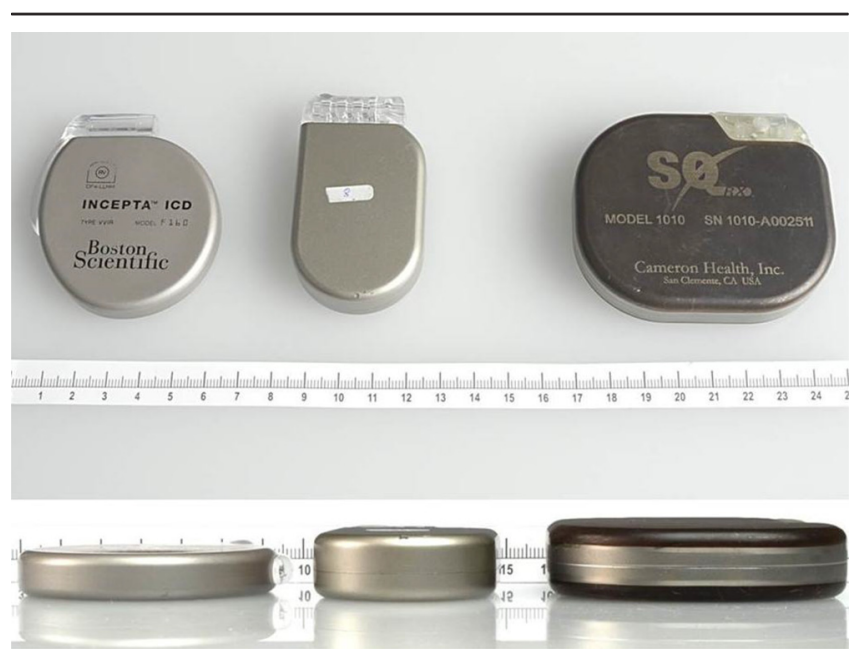

The subcutaneous ICD can is larger and heavier than conventional ICD systems because of a higher defibrillation threshold.

conventional systems, and so earlier battery changes are inevitable. Next generations of the S-ICD are expected with more battery capacity and smaller volume.

Three sensing poles allow the system to use three vectors for arrhythmia detection: the proximal and distal pole of the electrode and the generator itself. Thus, three sensing vectors can be used for arrhythmia detection (Figures 3 and 4):

- primary vector (that is, proximal electrode ring to can)

- secondary vector (that is, distal electrode ring to can)

- alternate vector (that is, distal electrode ring to proximal electrode ring)

The system automatically chooses the best vector for detection after implantation on the basis of highest $\mathrm{R}$ amplitude, best noise reduction, and $\mathrm{R}$ - to T-wave ratio to avoid double QRS counting and T-wave oversensing. Of note, an electrocardiogram screening prior to the implantation of the S-ICD System has to be fulfilled carefully to ensure patient eligibility for an S-ICD in no fewer than two postures. At least one vector has to be acceptable in both postures, but we always demand at least two appropriate vectors per posture to have the opportunity of manual change of sensing vectors. Owing to the lack of an adequate vector, about $15 \%$ of S-ICD candidates will not qualify for eligibility for the system [13]. It should be noted that this is an estimation of only one study and may vary according to different populations. 
Figure 3. Sensing vectors of the subcutaneous implantable cardioverter defibrillator

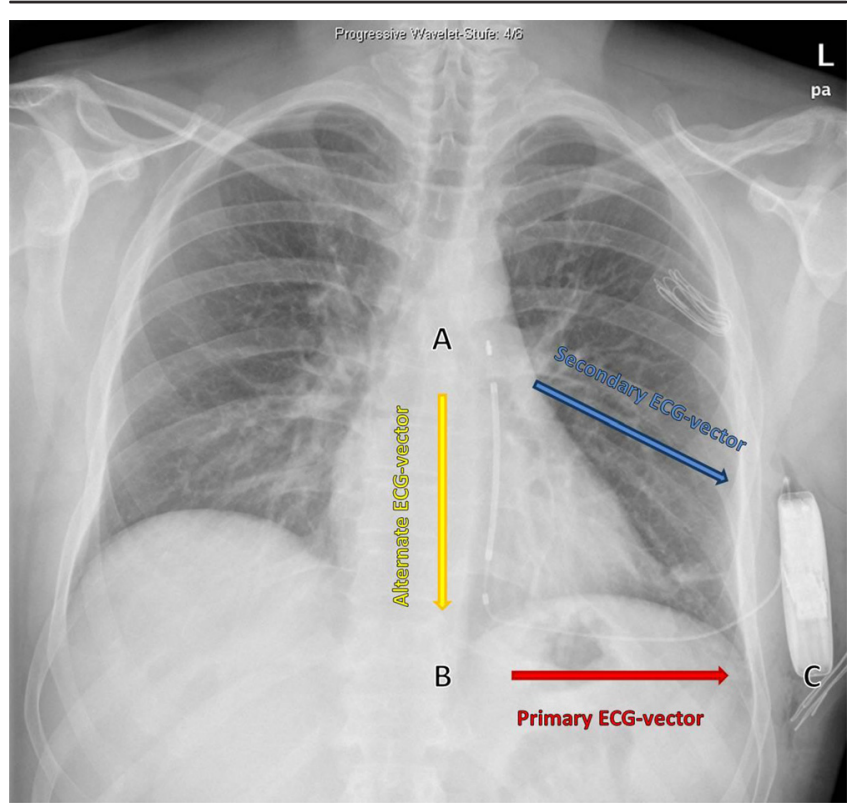

(A) Distal electrode ring; (B) proximal electrode ring; (C) can. Primary vector from proximal electrode ring to can (red arrow), secondary vector from distal electrode ring to can (blue arrow) and alternate vector from distal electrode ring to proximal electrode ring (yellow arrow) are shown. Abbreviations: ECG, electrocardiogram.

The detection zone can be programmed from 170-250 beats per minute (bpm) in 10-bpm intervals, with the option to program a two-zone therapy: a shock zone, in which the only criterion is the actual heart rate, and an optional conditional zone for rhythm discrimination. In the latter zone, additional morphology criteria (that is, QRS width) are used to discriminate shockable rhythms from supraventricular tachycardias. The conditional shock zone should be programmed routinely to avoid inappropriate shocks due to the recently published 1-year follow-up results from the Evaluation of Factors Impacting Clinical Outcome and Cost Effectiveness of the S-ICD (EFFORTLESS S-ICD) Registry [14]. This nonrandomized multicenter registry has collected data from seven countries since June 2009. In this registry, dualzone programming had a $6.4 \%$ inappropriate shock rate whereas single-zone programming had a $12 \%$ rate. Gold and colleagues [15] recently showed that a dual-zone programming reduced inappropriate shocks with the S-ICD System and did not result in prolongation of detection times or increased syncope.

After delivering a shock, the S-ICD System allows an optional post-shock pacing on demand for up to 30 seconds if the actual heart rate is below $50 \mathrm{bpm}$.
Figure 4. Lateral chest $x$-ray of the implanted subcutaneous implantable cardioverter defibrillator

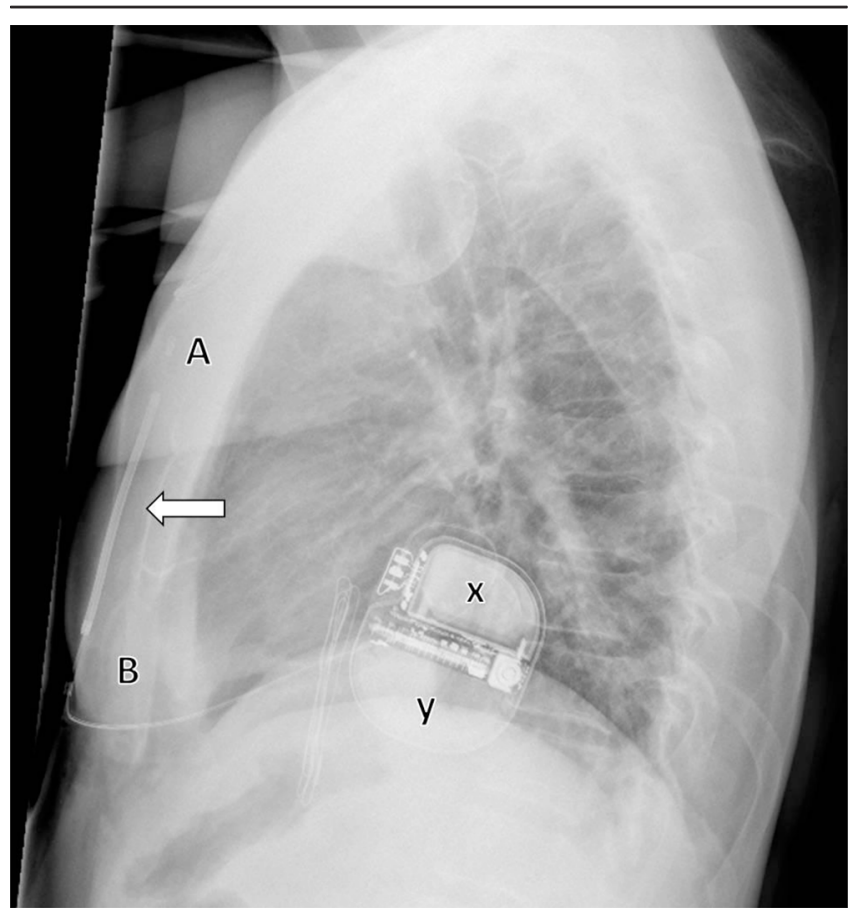

The shock coil (arrow) is flanked by the two sensing poles: distal $(A)$ and proximal (B) electrode ring. (x) Battery; $(y)$ capacitor.

However, the S-ICD System does not provide long-term pacing (as this leads to continuous thoracic stimulation with discomfort for the patient) and therefore cannot be recommended in patients with symptomatic bradycardia or need for cardiac resynchronization therapy or ATP. Accordingly, it is important to rule out these contraindications before implanting the device.

Because of the limited experience and lack of long-term follow-up data so far, it is advised to always test the system after implantation unless contraindications such as an intracavitary thrombus or hemodynamic impairment exclude a defibrillation test. A 15-J safety margin is generally recommended. As a personal preference, we induce two consecutive episodes with two shock energy levels (first shock with $65 \mathrm{~J}$ and, in case of successful termination, a second shock with $55 \mathrm{~J}$ ) to ensure the ability of the S-ICD System to sense and terminate VF appropriately. In case of an unsuccessful test, the shock vector will be changed to reversed. In some cases, a repositioning of the generator or lead was needed to obtain a successful defibrillation test.

\section{Which patient may benefit from a subcutaneous implantable cardioverter defibrillator system?}

Candidates for the implantation of the S-ICD are patients who are not expected to benefit from pacing options 
(for example, ATP or cardiac resynchronization therapy) of modern ICD devices. In our experience, this includes, for example, patients with hypertrophic cardiomyopathy or ion channelopathies-such as QT syndromes, Brugada syndrome, idiopathic VF, catecholaminergic polymorphic ventricular tachycardia (VT), and early repolarization syndrome-and patients with structural heart disease implanted for primary prevention of SCD. Indications in the EFFORTLESS registry were ischemic cardiomyopathy (37\%), idiopathic VF $(8 \%)$, inherited channelopathies $(13 \%)$, congenital heart disease (7\%), and non-ischemic cardiomyopathy (31\%) [14].

Performing a precise patient screening and choosing the optimal sensing vector during rest in different positions reduce the risk of T-wave oversensing. In addition, exercise testing with maximum tolerable capacity should be performed routinely, especially in patients with ion channel disorders and hypertrophic cardiomyopathy. In a study by Olde Nordkamp and colleagues [16], hypertrophic cardiomyopathy, a heavy weight, a prolonged QRS duration, and an R- to T-wave ratio of less than 3 in the electrocardiogram lead with the largest $\mathrm{T}$ wave were independently associated with screening failure.

Besides, patients with complex anatomy or lack of venous access (for example, venous occlusion, previous infection and extraction of a conventional system, or vascular abnormalities of grown-ups with congenital heart disease) (or both) or a history of lead infection may be good candidates for the complete subcutaneous device.

Young patients may also be suitable candidates because of an expected high percentage of possible lead failures in this group.

Although the system is used successfully even in children as shown in the EFFORTLESS registry [14], an implantation in patients with a weight below 30-35 kg should be considered very carefully on the basis of the relatively large and heavy generator [17].

One may also consider S-ICD for primary prevention of SCD for more common indications such as dilated cardiomyopathy or post-myocardial infarction patients. In case a VT requiring ATP occurs, a system conversion to a conventional transvenous ICD device has to be considered. In primary prevention, a two-step approach may also be recommended to delay endocardial lead implantation. In a trial by Abkenari and colleagues [18], six shocks were delivered for $\mathrm{VT}$ in one patient. As a result, the S-ICD was explanted and replaced by a conventional transvenous system to allow ATP. This two-step approach may also be used for prevention of
SCD in patients with coronary artery disease or dilated cardiomyopathy.

To analyze arrhythmia discrimination of the S-ICD System, the Subcutaneous versus Transvenous Arrhythmia Recognition Testing (START) trial [19] directly compared arrhythmia detection of the S-ICD with singleor dual-chamber transvenous ICDs using simultaneous arrhythmia recordings. Whereas sensitivity in S-ICD and transvenous devices showed very similar results, specificity was significantly better in the S-ICD System than in single- or dual-chamber transvenous ICD. Thus, the S-ICD could be an interesting device to reduce inappropriate shocks in patients with coexistent asymptomatic atrial fibrillation, which is the most frequent reason for inappropriate shocks in conventional systems [20]. However, the existing limited data on S-ICD also reported a high rate of inappropriate ICD shocks with S-ICD. The reported rates range between $7 \%$ and $16 \%$ (Table 1). Most of that was due to either T-wave oversensing or failure to program a dual-zone therapy.

Despite the limited reported implant- and lead-related complications, there are some patients who may not profit from the S-ICD. Patients with ischemic cardiomyopathy are much more likely to have monomorphic VTs, which may require ATP, and are more likely to benefit from a transvenous ICD system. However, given the data from the Sudden Cardiac Death in Heart Failure Trial (SCD-HeFT) [5], the percentage of primary prevention patients receiving ICD therapy was $21 \%$ in 3 years. It is therefore a trade-off between the risks of transvenous lead complications versus the possibility of VT that might be stopped by ATP instead of a shock.

Moreover, in secondary prevention, for example, in patients with a history of sustained monomorphic VTs, a conventional system clearly is the better choice. The results of the Pacing Fast Ventricular Tachycardia Reduces Shock Therapies (PainFREE Rx II) Trial showed that empirical ATP for fast VT is as effective and safe as an internal shock [21]. In this trial, 634 ICD patients were randomly assigned to either empirical ATP or shock programming for the initial therapy of a fast VT (188-250 bpm). ATP was successful in 229 of 284 episodes in the ATP group $(81 \%)$, but $50 \%$ of all ATP was received by only two patients. There was no significant difference concerning acceleration, syncope, or SCD. Of note, spontaneous termination of VT episodes was observed in $34 \%$ in the shock arm, whereas no spontaneous termination occurred in the ATP group, because all VTs were treated by ATP. 


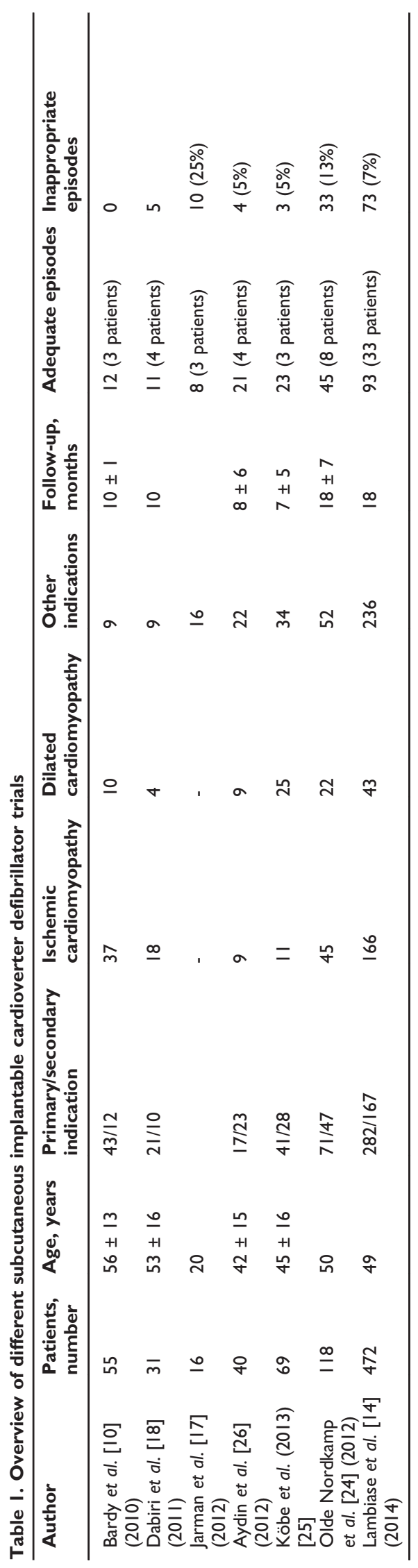

Page 5 of 10 
In addition, some trials showed that ICD shocks are associated with a higher mortality and limited prognosis [22], which favors the benefit of ATP. Given the reduction in quality of life due to ICD shocks, ATP remains an important part in the therapy of VT. In the Multicenter Automatic Defibrillator Implantation Trial II (MADIT II), VT occurred in $25 \%$ of all patients within 3 years, who were not inducible in electrophysiology studies prior to implantation. If repeated VT and subsequent shocks occur in patients with an S-ICD, this may of course have consequences for quality of life as well as battery longevity [22]. Patients in need of pacing due to bradycardia or cardiac resynchronization therapy are also not candidates for the current S-ICD. In patients with a small body mass index, the implantation has to be considered very carefully because of potential wound healing disorders.

\section{Safety and efficacy of the subcutaneous implantable cardioverter defibrillator: results from clinical trials}

Compared with data on conventional ICD, those on S-ICD are still limited. Initial trials by Bardy and colleagues [10] have demonstrated short-term safety and efficacy of the S-ICD System. In a pilot study with 6 patients, 18 induced episodes of VF during the implantation procedure were detected appropriately. However, defibrillation threshold was significantly higher in the S-ICD (S-ICD versus ICD $36.6 \pm 19.8 \mathrm{~J}$ versus $11.1 \pm 8.5 \mathrm{~J}$ ) [10].

Olde Nordkamp and colleagues [23] evaluated efficacy and safety of the S-ICD in a Dutch cohort with 118 patients and a follow-up with 177 patient-years. In this registry, 8 patients received 45 successful appropriate shocks with a first shock conversion efficacy of $98 \%$. S-ICD-related complications were observed in $14 \%$. Because of lead dislocation in two patients, this study led to the introduction of an additional suture sleeve at the xiphoid. Seven patients experienced infection of the system, which required explantation of the system. Interestingly, the investigators observed that relatively more inappropriate shocks and complications occurred in the first patients. So they concluded that there was both a physician- and device-related learning curve.

Furthermore, the European clinical trial, which enrolled 55 patients, showed accurate detection and termination of induced VF in almost all patients, with 12 episodes of spontaneous VF in 3 patients during the follow-up [10]. A large multicenter trial for US Food and Drug Administration approval in the US evaluating the safety and efficacy with 330 enrolled patients (314 with successful implantation) was published in 2013 by Weiss and colleagues [24]. In this trial, 897 (99.8\%) of
899 induced VF episodes during acute or chronic testing were detected and terminated successfully. Subsequent testing demonstrated acceptable detection of VF in the two unsuccessful cases. In total, 119 spontaneous VT/VF episodes occurred in 21 patients; 38 appeared as isolated episodes and 81 within an electrical storm. Successful termination of the ventricular arrhythmia was achieved in 37 of 38 isolated episodes $(97.4 \%)$ and in all VT storm episodes. One episode terminated during charge to deliver a second shock. No death due to ventricular arrhythmia occurred in this study. We performed a case control study on 69 patients [25]. In this study, failure of conversion of induced VF episodes occurred in $10.4 \%$. In one patient, a severe hematoma led to a revision of the S-ICD System.

In the recent early data from the EFFORTLESS S-ICD Registry, 169 therapies were delivered in 59 (13\%) of 456 patients [14]. Ninety-three of these therapies were appropriate for ventricular tachyarrhythmias. The efficacy of first shock was $88 \%$; overall shock conversion efficacy was $100 \%$ after delivering a maximum of five shocks.

Of note, Aydin and colleagues [26] reported failure of the S-ICD shock even after successful intraoperative testing; in their study, first-shock efficacy was only $57.9 \%$. Therefore, further prospective data are required before the definite role of S-ICD for prevention of SCD will be defined.

\section{Side-effects and complications of subcutaneous implantable cardioverter defibrillator}

Given that the implantation procedure is performed subcutaneously, perioperative complications are rare. Compared with transvenous systems, typical procedural complications (such as vascular lesions, pneumothorax, cardiac tamponade, perforation, and post-operative electrode dislocation) are omitted.

\section{Inappropriate shocks}

With regard to inappropriate shocks, Weiss and colleagues [24] reported an incidence of about 13\%. In 5\%, a shock was delivered because of supraventricular tachycardia, but no patient received an inappropriate shock in the conditional zone. Thus, programming of a conditional zone significantly reduced the risk of inappropriate shocks for supraventricular tachycardia (70\% relative risk reduction). The most common reason for inappropriate shocks was T-wave oversensing (in $8 \%$ ) (Figures 5 and 6). In particular, patients with hypertrophic cardiomyopathy and Brugada syndrome seem to be at risk because of repolarization related T-wave changes during exercise. Especially in these patients, an 
Figure 5. Adequate episode which is terminated by the subcutaneous implantable cardioverter defibrillator
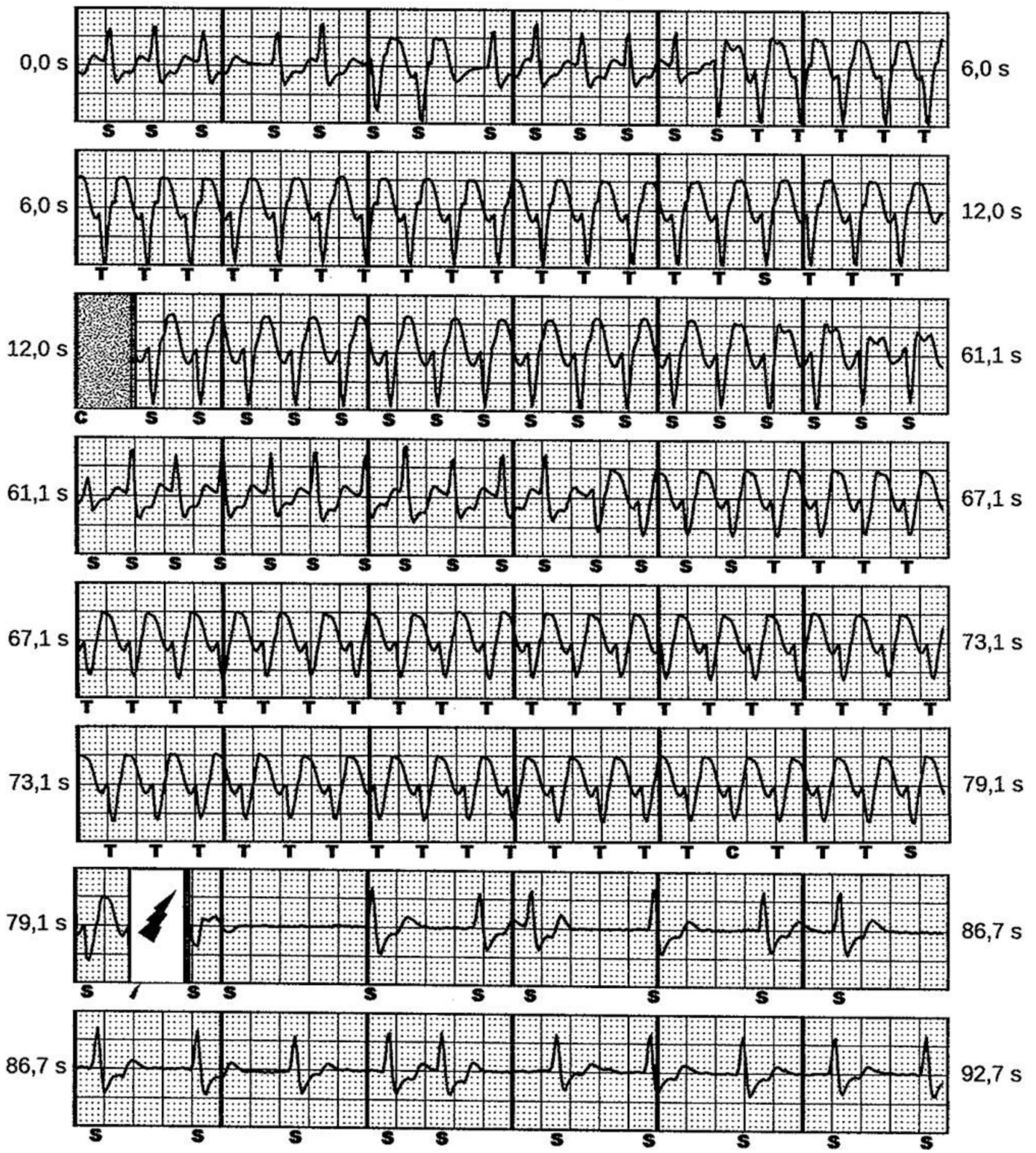

Out of tachycardiac atrial fibrillation results a sudden onset of a monomorphic ventricular tachycardia (change of axis, wide QRS complexes). First the ventricular tachycardia (VT) is sustained for over I3 seconds, then terminates spontaneously. Then, the VT recurs and is regular, detected and successfully terminated with the first 80 -J shock. Post-shock normal sinus rhythm is observed with premature supraventricular beats. 
Figure 6. Inappropriate shock due to T-wave oversensing
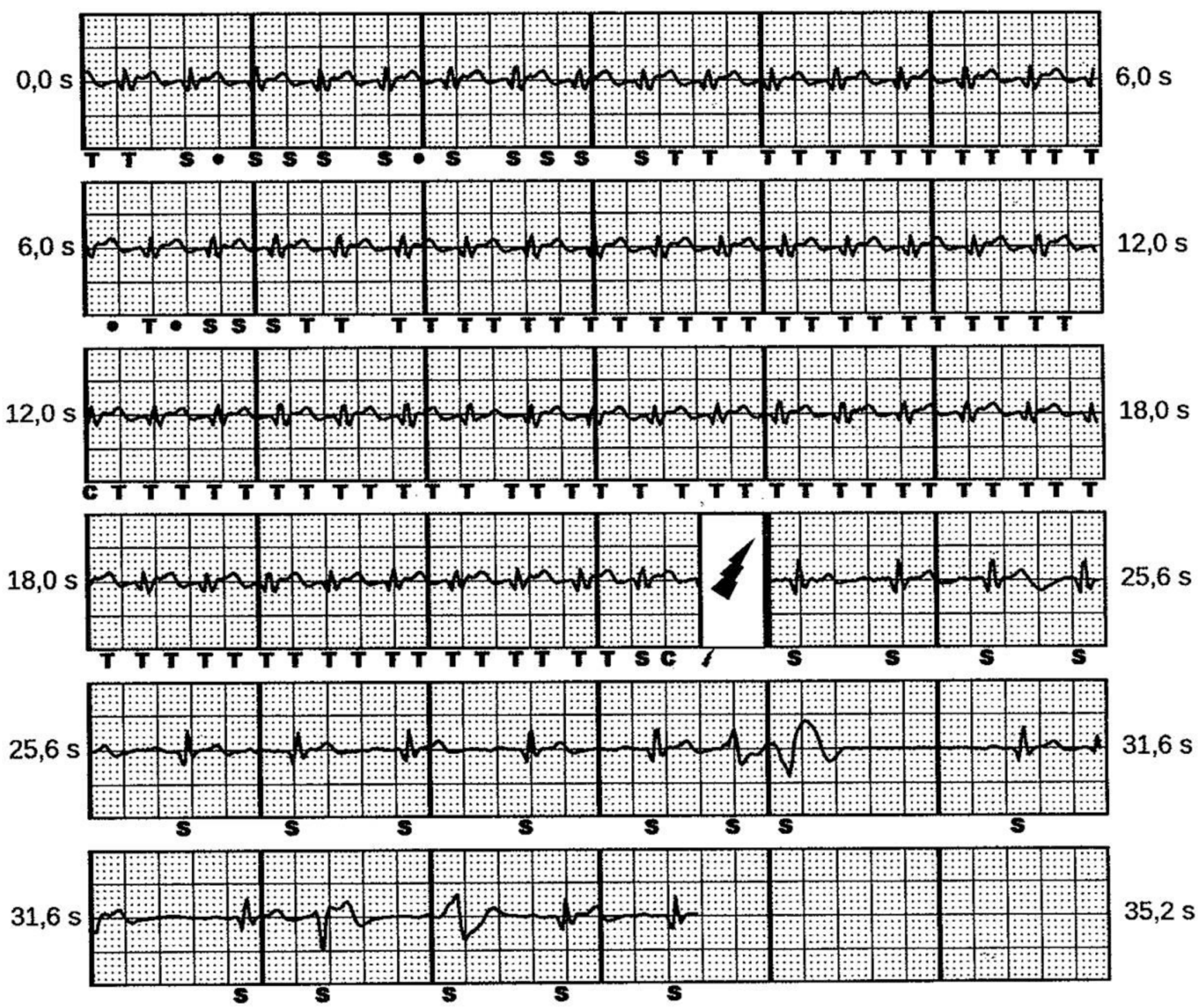

The amplitude of the T waves is nearly as high as the QRS complexes. Hence, the double-counting of QRS complexes led to an inappropriate shock.

exercise test should be performed prior to discharge to detect possible $\mathrm{T}$-wave oversensing. In such a case, manual change of the sensing vector can almost always effectively avoid T-wave oversensing. Therefore, it is reasonable to ensure that no fewer than two vectors show adequate sensing in pre-implant patient screening. In the EFFORTLESS registry, 73 inappropriate shocks were recorded in 32 patients over an average follow-up of 18 months [14]. Oversensing was the major cause of inappropriate shocks in $85 \%$. The inappropriate shock rate with single-zone programming was higher than the inappropriate shock rate with dual-zone programming (12\% versus $6.4 \%)$.

\section{Infections}

Worth mentioning are infections of the generator pocket, which is seen in different trials from $2-10 \%$ and in some cases resulted in explantation of the system (Table 1). Of 111 patients in the early UK experience of S-ICD, 4\% got device-related infections that led to explantation of the system [27]. A similar occurrence was reported by the EFFORTLESS Investigators [14] with procedure-related infections in about $4 \%$, resulting in explantation of the system in about $2 \%$. Weiss and colleagues [24] showed a decrease in infections in their study attributed to a learning curve. They reported four cases of infections that required explantation of the system and three of those 
cases occurred in the first third of the study. In our multicenter case control study [25], 1 out of 18 patients developed a massive hematoma in the presence of oral anticoagulation, which had to be treated operatively.

\section{Conclusions}

The S-ICD System is emerging as a safe and efficient supplement to conventional transvenous ICD Systems in a wide range of indications in patients who do not require pacing. The first clinical data showed high efficacy of the S-ICD system to treat induced and spontaneous ventricular arrhythmias. Published series reported a variety of indications for S-ICD (Table 1). A lot of patients have rare underlying diseases. However, as seen in the EFFORTLESS registry [14], the most frequent underlying disease in patients with S-ICD still was ischemic cardiomyopathy (in $37 \%$ of all patients). In particular, young patients who require several expected lead changes in life may profit from the S-ICD.

The rates of perioperative and long-term complications reported so far are low, and endocardial lead associated complications seem to be eliminated. Avoidance of inappropriate shock delivering due to T-wave oversensing and pocket infections are still problems to solve. However, advances have led to less complications with the implant procedure and a decrease in inappropriate shocks since the first human implant experience $(17 \%)$, to now less than $7 \%[10,14]$. An upgrade of S-ICD software for sensing algorithms to avoid T-wave oversensing has been provided by the manufacturer recently. Furthermore, expansion of programming parameters and remote (radio frequency telemetered) followup of device function would be desirable. The ongoing Prospective, Randomized Comparison of Subcutaneous and Transvenous Implantable Cardioverter-Defibrillator Therapy (PRAETORIAN) trial compares S-ICD with transvenous systems [28]. Whether next generations of the S-ICD will reduce the concerns regarding T-wave oversensing, infections, and relatively short battery longevity remains to be seen in the future.

\section{Abbreviations}

ATP, antitachycardic pacing; bpm, beats per minute; EFFORTLESS, Evaluation of Factors Impacting Clinical Outcome and Cost Effectiveness; ICD, implantable cardioverter defibrillator; SCD, sudden cardiac death; S-ICD, subcutaneous implantable cardioverter defibrillator; $\mathrm{VF}$, ventricular fibrillation; VT, ventricular tachycardia.

\section{Disclosures}

Lars Eckardt and Florian Reinke have received lecture honorary from Boston Scientific and were members of the scientific advisory board of Cameron Health. The other authors declare that they have no competing interests.

\section{References}

I. Fishman GI, Chugh SS, Dimarco JP, Albert CM, Anderson ME, Bonow RO, Buxton $A E$, Chen $P$, Estes $M$, Jouven $X$, Kwong $R$, Lathrop DA, Mascette AM, Nerbonne JM, O'Rourke B, Page RL, Roden DM, Rosenbaum DS, Sotoodehnia N, Trayanova NA, Zheng Z: Sudden cardiac death prediction and prevention: report from a National Heart, Lung, and Blood Institute and Heart Rhythm Society Workshop. Circulation 2010, 122:2335-48.

\section{FlOOOPrime}

\section{RECOMMENDED}

2. Mirowski M, Reid PR, Mower MM, Watkins L, Gott VL, Schauble JF, Langer A, Heilman MS, Kolenik SA, Fischell RE, Weisfeldt ML: Termination of malignant ventricular arrhythmias with an implanted automatic defibrillator in human beings. $N$ Engl J Med 1980, 303:322-4.

3. Moss AJ, Hall WJ, Cannom DS, Daubert JP, Higgins SL, Klein H, Levine JH, Saksena S, Waldo AL, Wilber D, Brown MW, Heo M: Improved survival with an implanted defibrillator in patients with coronary disease at high risk for ventricular arrhythmia. Multicenter Automatic Defibrillator Implantation Trial Investigators. N Engl J Med 1996, 335:1933-40.

4. Moss AJ, Zareba W, Hall WJ, Klein H, Wilber DJ, Cannom DS, Daubert JP, Higgins SL, Brown MW, Andrews ML: Prophylactic implantation of a defibrillator in patients with myocardial infarction and reduced ejection fraction. N Engl J Med 2002, 346:877-83.

\section{FlOOOPrime
RECOMMENDED}

5. Bardy GH, Lee KL, Mark DB, Poole JE, Packer DL, Boineau R, Domanski M, Troutman C, Anderson J, Johnson G, McNulty SE, Clapp-Channing N, Davidson-Ray LD, Fraulo ES, Fishbein DP, Luceri RM, Ip JH: Amiodarone or an implantable cardioverter-defibrillator for congestive heart failure. N Engl J Med 2005, 352:225-37.

\section{FlOOOPrime}

6. Alter P, Waldhans S, Plachta E, Moosdorf R, Grimm W: Complications of implantable cardioverter defibrillator therapy in $\mathbf{4 4 0}$ consecutive patients. Pacing Clin Electrophysiol 2005, 28:926-32.

\section{FIOOOPrime}

7. Neuzil P, Taborsky M, Rezek Z, Vopalka R, Sediva L, Niederle P, Reddy V: Pacemaker and ICD lead extraction with electrosurgical dissection sheaths and standard transvenous extraction systems: results of a randomized trial. Europace 2007, 9:98-104.

\section{FlOOOPrime}

RECOMMENDED

8. Maisel WH, Kramer DB: Implantable cardioverter-defibrillator lead performance. Circulation 2008, I I 7:272 I-3.

\section{FlOOOPrime \\ RECOMMENDED}

9. Hauser RG, Katsiyiannis WT, Gornick CC, Almquist AK, Kallinen LM: Deaths and cardiovascular injuries due to device-assisted implantable cardioverter-defibrillator and pacemaker lead extraction. Europace 2010, 12:395-40I.

\section{FlOOOPrime}

10. Bardy GH, Smith WM, Hood MA, Crozier IG, Melton IC, Jordaens L, Theuns D, Park RE, Wright DJ, Connelly DT, Fynn SP, Murgatroyd FD, Sperzel J, Neuzner J, Spitzer SG, Ardashev AV, Oduro A, Boersma L, Maass AH, Van Gelder, Isabelle C, Wilde AA, 
van Dessel , Pascal F, Knops RE, Barr CS, Lupo P, Cappato R, Grace AA: An entirely subcutaneous implantable cardioverter-defibrillator. N Engl J Med 2010, 363:36-44.

\section{FlOOOPrime}

\section{RECOMMENDED}

II. Zumhagen S, Grace AA, O'Connor S, Löher A, Köbe J, Eckardt L, Schulze-Bahr E: Totally subcutaneous implantable cardioverter defibrillator with an alternative, right parasternal, electrode placement. Pacing Clin Electrophysiol 2012, 35:e254-7.

12. Knops RE, Olde Nordkamp LR, de Groot JR, Wilde AA: Two-incision technique for implantation of the subcutaneous implantable cardioverter-defibrillator. Heart Rhythm 2013, 10:1240-3.

\section{FlOOOPrime}

\section{RECOMMENDED}

13. Randles DA, Hawkins NM, Shaw M, Patwala AY, Pettit SJ, Wright DJ: How many patients fulfil the surface electrocardiogram criteria for subcutaneous implantable cardioverter-defibrillator implantation? Europace 2014, 16:1015-2I.

\section{FlOOOPrime
RECOMMENDED}

14. Lambiase PD, Barr C, Theuns DA, Knops R, Neuzil P, Johansen JB, Hood M, Pedersen S, Kääb S, Murgatroyd F, Reeve HL, Carter N, Boersma L, EFFORTLESS Investigators: Worldwide experience with a totally subcutaneous implantable defibrillator: early results from the EFFORTLESS S-ICD Registry. Eur Heart J 2014, 35:1657-65.

\section{FIOOOPrime}

15. Gold MR, Weiss R, Theuns DA, Smith W, Leon A, Knight BP, Carter N, Husby M, Burke MC: Use of a discrimination algorithm to reduce inappropriate shocks with a subcutaneous implantable cardioverter-defibrillator. Heart Rhythm 2014, I I:1352-8.

\section{FlOOOPrime}

\section{RECOMMENDED}

16. Olde Nordkamp LR, Warnaars JL, Kooiman KM, de Groot JR, Rosenmöller BR, Wilde AA, Knops RE: Which patients are not suitable for a subcutaneous ICD: incidence and predictors of failed QRS-T-wave morphology screening. J Cardiovasc Electrophysiol 2014, 25:494-9.

\section{FlOOOPrime}

17. Jarman JW, Lascelles $\mathrm{K}$, Wong $\mathrm{T}$, Markides $\mathrm{V}$, Clague JR, Till J: Clinical experience of entirely subcutaneous implantable cardioverter-defibrillators in children and adults: cause for caution. Eur Heart J 2012, 33:1351-9.

\section{FIOOOPRime}

18. Dabiri Abkenari L, Theuns DA, Valk SD, van Belle Y, de Groot NM, Haitsma D, Muskens-Heemskerk A, Szili-Torok T, Jordaens L: Clinical experience with a novel subcutaneous implantable defibrillator system in a single center. Clin Res Cardiol 20I I, 100:737-44.

\section{FIOOOPrime}

19. Gold MR, Theuns DA, Knight BP, Sturdivant JL, Sanghera R, Ellenbogen KA, Wood MA, Burke MC: Head-to-head comparison of arrhythmia discrimination performance of subcutaneous and transvenous ICD arrhythmia detection algorithms: the START study. J Cardiovasc Electrophysiol 2012, 23:359-66.

\section{FlOOOPrime \\ RECOMMENDED}

20. van Rees JB, Borleffs CJ, de Bie MK, Stijnen T, van Erven L, Bax JJ, Schalij MJ: Inappropriate implantable cardioverter-defibrillator shocks: incidence, predictors, and impact on mortality. I Am Coll Cardiol 20I I, 57:556-62.

\section{FIOOOPrime}

21. Wathen MS, DeGroot PJ, Sweeney MO, Stark AJ, Otterness MF, Adkisson WO, Canby RC, Khalighi K, Machado C, Rubenstein DS, Volosin KJ, PainFREE rx II Investigators: Prospective randomized multicenter trial of empirical antitachycardia pacing versus shocks for spontaneous rapid ventricular tachycardia in patients with implantable cardioverter-defibrillators: Pacing Fast Ventricular Tachycardia Reduces Shock Therapies (PainFREE Rx II) trial results. Circulation 2004, I I 0:259|-6.

\section{FIOOOPrime}

RECOMMENDED

22. Daubert JP, Zareba W, Cannom DS, McNitt S, Rosero SZ, Wang P, Schuger C, Steinberg JS, Higgins SL, Wilber DJ, Klein H, Andrews ML, Hall WJ, Moss AJ, MADIT II Investigators: Inappropriate implantable cardioverter-defibrillator shocks in MADIT II: frequency, mechanisms, predictors, and survival impact. J Am Coll Cardiol 2008, 5 I: 1357-65.

\section{FlOOOPrime
RECOMMENDED}

23. Olde Nordkamp R, Dabiri Abkenari L, Boersma LV, Maass AH, de Groot JR, van Oostrom AJ, Theuns DA, Jordaens LJ, Wilde AA, Knops RE: The entirely subcutaneous implantable cardioverter-defibrillator: initial clinical experience in a large Dutch cohort. J Am Coll Cardiol 2012, 60:1933-9.

\section{FlOOOPrime
RECOMMENDED}

24. Weiss R, Knight BP, Gold MR, Leon AR, Herre JM, Hood M, Rashtian M, Kremers M, Crozier I, Lee KL, Smith W, Burke MC: Safety and efficacy of a totally subcutaneous implantablecardioverter defibrillator. Circulation 2013, I 28:944-53.

\section{FIOOOPrime}

RECOMMENDED

25. Köbe J, Reinke F, Meyer C, Shin D, Martens E, Kääb S, Löher A, Amler S, Lichtenberg A, Winter J, Eckardt L: Implantation and follow-up of totally subcutaneous versus conventional implantable cardioverter-defibrillators: a multicenter casecontrol study. Heart Rhythm 2013, 10:29-36.

26. Aydin A, Hartel F, Schlüter M, Butter C, Köbe J, Seifert M, Gosau N, Hoffmann B, Hoffmann M, Vettorazzi E, Wilke I, Wegscheider K, Reichenspurner H, Eckardt L, Steven D, Willems S: Shock efficacy of subcutaneous implantable cardioverter-defibrillator for prevention of sudden cardiac death: initial multicenter experience. Circ Arrhythm Electrophysiol 2012, 5:913-9.

\section{FlOOOPrime
RECOMMENDED}

27. Jarman, Julian W E, Todd DM: United Kingdom national experience of entirely subcutaneous implantable cardioverter-defibrillator technology: important lessons to learn. Europace 2013, 15:1158-65.

\section{FlOOOPrime \\ RECOMMENDED}

28. Olde Nordkamp LR, Knops RE, Bardy GH, Blaauw Y, Boersma LV, Bos JS, Delnoy PP, van Dessel PF, Driessen AH, de Groot JR, Herrman JP, Jordaens LJ, Kooiman KM, Maass AH, Meine M, Mizusawa Y, Molhoek SG, van Opstal J, Tijssen, Jan GP, Wilde AA: Rationale and design of the PRAETORIAN trial: a Prospective, RAndomizEd comparison of subcuTaneOus and tRansvenous ImpIANtable cardioverter-defibrillator therapy. Am Heart J 2012, 163:753-760.e2. 